\title{
THE ACCURACY AND RELIABILITY OF COMMERCIAL HEART RATE MONITORS
}

\author{
M. J. BURKE, MSc* and M. V. WHELAN, PhD** \\ *Research Student, and **Professor of Microelectronics and Electrical Engineering, Trinity College, Dublin
}

\section{ABSTRACT}

In recent years increasing emphasis has been placed on the benefits of exercise to normal healthy adults as well as to those recovering from heart attacks and other illnesses. As an aid to exercise training many portable heart-rate monitors have been placed on the market but little appears to have been done to assess the performance of these machines. The authors have examined the performance of four such monitors both under bench-test and practical exercising conditions.

When tested on the bench using electronic equipment, the machines rarely exhibited errors exceeding 2-3 bpm over a measurement range of 30-240 bpm. However, when tested with subjects walking or jogging at low speeds on a treadmill, typically $\mathbf{2 0 - 7 0 \%}$ of the readings given by the machines had errors of greater than $20 \mathrm{bpm}$. In some cases over $50 \%$ of readings had errors exceeding $50 \mathrm{bpm}$.

Key words: Heart rate, Monitoring, Accuracy, Reliability, Exercise.

\section{INTRODUCTION}

Regular physical exercise has been shown to help maintain fitness and to decrease the risks of high blood-pressure, cardiovascular disease and heart-attack (Adams et al, 1981; Blair et al, 1984; Graettinger, 1984; Paffenbarger and Hyde, 1980; Paffenbarger et al, 1984). It has also been shown to be beneficial to some, but not all, patients recovering from heart attacks (Andrews et al, 1981; Harris, 1970). This has led to a marked increase in the number of people participating in leisure sporting activities, amateur athletics and, in particular, jogging.

People who have previously led a sedentary lifestyle or who have suffered a heart attack face the danger of overstressing their bodies when beginning an exercise programme. Professional athletes also face the danger of overstress when undergoing rigorous training. As a precaution, therefore, athletes and joggers are commonly advised to check their heart rate during exercise and to keep it within defined guidelines. This maximises the benefits of training while minimising the risk of overstress (Fox, 1979; Glover and Sheperd, 1978; Jensen and Fisher, 1979; Morehouse, 1972).

As an aid to exercise training, many portable heart rate monitors have been marketed which continuously measure and display the user's heart rate during exercise. Despite the importance of these machines little seems to have been done to assess their accuracy and reliability. This article reports the evaluation of the performance of four of these monitors.

\section{MATERIALS AND METHOD}

Four machines designated $A, B, C$ and $D$ were tested. The machines are basically of two different types: Machine $A$ picks up an electrical, ECG-related signal by means of two electrodes. One consists of the metal back of a wrist watch which makes contact with the wrist on which it is placed. The other consists of a metal sensing pad on the front of the watch onto which the tip of a finger from the other hand is placed. The signal thus detected is amplified internally and used to determine the heart rate, the value of which is then shown on a liquid crystal display. Machines $B, C$ and $D$, on the other hand, use infra-red phototransducers to detect the blood-volume pulse in the user's finger and produce a

Address for correspondence:

Mr. M. J. Burke

Dept. of Microelectronics and Electrical Engineering

Trinity College

Dublin 2 corresponding electrical signal. This signal is then amplified and used to determine the heart rate which is again shown on a liquid crystal display.

Two series of tests were carried out on each machine. The first comprised of testing their accuracy using electronic equipment. The second entailed comparative measurements of the in vivo heart rates of several subjects while exercising on a treadmill.

\section{Electronic Testing}

(a) Sinewave Signal A sinewave signal generator (Wavetek 180 LF) was used to modulate a current source which fed an infra-red, light-emitting-diode (LED). The LED was placed close to the photodetector in the transducers of Machines B, $C$ and $\mathrm{D}$. The photodetector responded to the modulated light as a signal representing the pulse. In the case of Machine A, however, the signal from the generator was fed directly to its sensing electrodes through a suitable coupling network.

The frequency of the signal was adjusted precisely in steps corresponding to the values of heart rate listed in Table I(a) in the range 30-240 beats per minute (bpm). The reading of heart rate displayed by the machine was recorded for each step. When the reading displayed altered over several values the maximum and minimum values were recorded.

(b) Composite Signals Each machine studied measured and displayed the heart rate in a different way. In order to establish in more detail how each machine operated, composite signals were substituted in place of the. sinewave signal. The composite signals simulated beat-tobeat changes in the heart rate by providing different durations between successive pulses as indicated in Table I(b). The sequences of readings displayed by each machine in response to the composite signals were recorded.

\section{Exercise Testing}

The accuracy and reliability of the machines were examined under more practical conditions by measuring the heart rates of several subjects while exercising on a motorised treadmill. The heart rates of four healthy young male subjects were measured with the subjects in each of the following states: (i) sitting relaxed on a stool, (ii) walking on the treadmill at a speed of $3 \mathrm{~km} \cdot \mathrm{hr}^{-1}$, (iii) jogging on the treadmill at a speed of $5 \mathrm{~km} \cdot \mathrm{hr}^{-1}$.

A standard, three-electrode (lead II) chest ECG signal was 
TABLE I

Results of electronic testing of the machines.

(a) SINUSOIDAL SIGNAL: Readings displayed by each machine in beats per minute

\begin{tabular}{|c|c|c|c|c|c|c|c|c|c|c|c|c|c|c|c|c|}
\hline $\begin{array}{l}\text { Heart rate of } \\
\text { test signal }\end{array}$ & 30 & 40 & 50 & 60 & 80 & 100 & 120 & 140 & 160 & 180 & 190 & 200 & 210 & 220 & 230 & 240 \\
\hline Machine A & - & 40 & - & 60 & 80 & $103 / 97$ & 120 & $140 / 138$ & 158 & 179 & 190 & $199 / 197$ & - & - & - & - \\
\hline Machine B & 30 & 40 & 50 & 60 & 80 & 100 & 120 & 140 & 160 & 179 & 189 & 192 & - & - & - & - \\
\hline Machine C & 30 & 40 & 50 & 60 & 80 & 100 & 120 & 140 & 160 & 180 & 190 & 199 & 209 & & & 240 \\
\hline Machine D & 30 & 40 & 50 & 60 & 80 & 100 & $1 / 120$ & & 161 & $181 / 180$ & $192 / 190$ & $201 / 200$ & $212 / 210$ & & & $242 / 240$ \\
\hline
\end{tabular}

Note: When the reading displayed by a machine varied over several values the maximum and minimum values were recorded.

(b) COMPOSITE SIGNALS:

Specification of Composite Signal A:

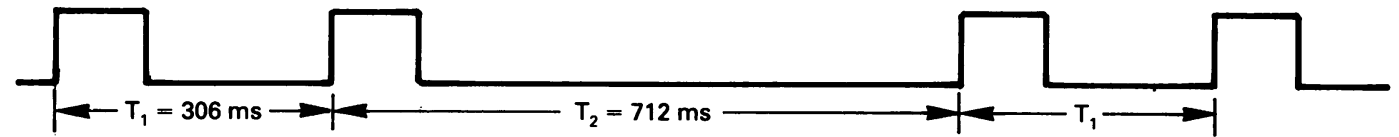

Note: $H R_{1}=60 / T_{1}=196 \mathrm{bpm} \quad H R_{2}=60 / T_{2}=84 \mathrm{bpm}$

Readings Displayed in Response to Composite Signal A:
Machine B
Reading of either 84 or 198 bpm displayed persistently.

\section{Machine C Reading of $118 \mathrm{bpm}$ displayed persistently.}

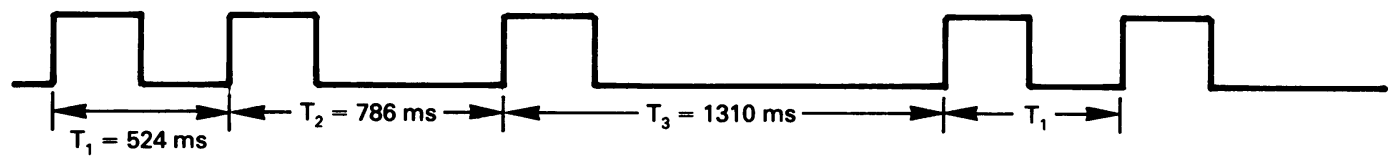

Note: $H R_{1}=60 / T_{1}=115 \mathrm{bpm}$

$$
H R_{2}=60 / T_{2}=77 \mathrm{bpm}
$$

$$
H R_{3}=60 / T_{3}=46 \mathrm{bpm}
$$

Readings Displayed in response to Composite Signal B:

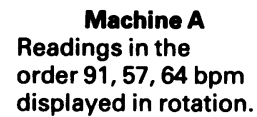

Machine C Reading of $66 \mathrm{bpm}$

\begin{tabular}{|c|c|}
\hline $\begin{array}{l}\text { Machine B } \\
\text { Readings in the } \\
\text { order } 114,76,46 \mathrm{bpm}\end{array}$ & $\begin{array}{l}\quad \text { Machine C } \\
\text { Reading of } 66 \mathrm{bpm} \\
\text { displayed persistently }\end{array}$ \\
\hline
\end{tabular}
displayed persistently
Machine D

Readings in the order

$73,65,68 \mathrm{bpm}$

displayed in rotation. obtained from a subject in the usual manner with precautions taken to minimise interference in the signal caused by movement. The signal was amplified by a factor of 2000 using an Oscillograh Recorder (Devices Ltd.). The amplified signal was then fed into a Ratemeter (Model 4522, Devices Ltd.), which incorporated threshold detection of the QRS complexes in the ECG signal to determine the beat-tobeat heart rate. The Ratemeter provided a step-like output voltage proportional to the beat-to-beat heart rate which was recorded on one channel of a flat-bed chart recorder (Rikadenki R-50). The accuracy of measurement was within $\pm 2 \mathrm{bpm}$ and a chart speed of $10 \mathrm{~cm} \cdot \mathrm{min}^{-1}$ allowed individual beat-to-beat variations in the heart rate to be identified as shown in Fig. 1.

An electronic timing and alarm circuit was constructed which emitted an audible "bleep" and a simultaneous electrical pulse at repeated intervals of 8 seconds. These pulses were recorded as event markers on a second channel of the chart recorder. An 8 second time interval was chosen because this was the regularity with which the display was updated on the machine which measured the heart rate over the longest period. This guaranteed that the same machine reading was not recorded twice during any given test. The test procedure was as follows: A subject was prepared for monitoring of his ECG in one of the test conditions listed above and the recording equipment set up accordingly. The heart rate monitor under test was strapped to his wrist and the transducer placed on his finger or otherwise, as appropriate. The treadmill was then activated when required, and its speed brought up slowly to that needed in the test.

The subject was then asked to call out the reading displayed by the machine immediately each time he heard a bleep. This reading was then written down by an observer beside the corresponding event marker on the chart. This was continued until 50 readings recorded at 8 second intervals had been obtained from the machine under test. This procedure was repeated with each machine on each subject under each of the three conditions listed above. Each test produced a record of the heart rate similar to that on the section of chart shown in Fig. 1.

\section{RESULTS}

\section{Electronic Testing}

Results of the electronic testing of the monitors are presented in Table I.

(a) Sinewave Signal The readings displayed by each 


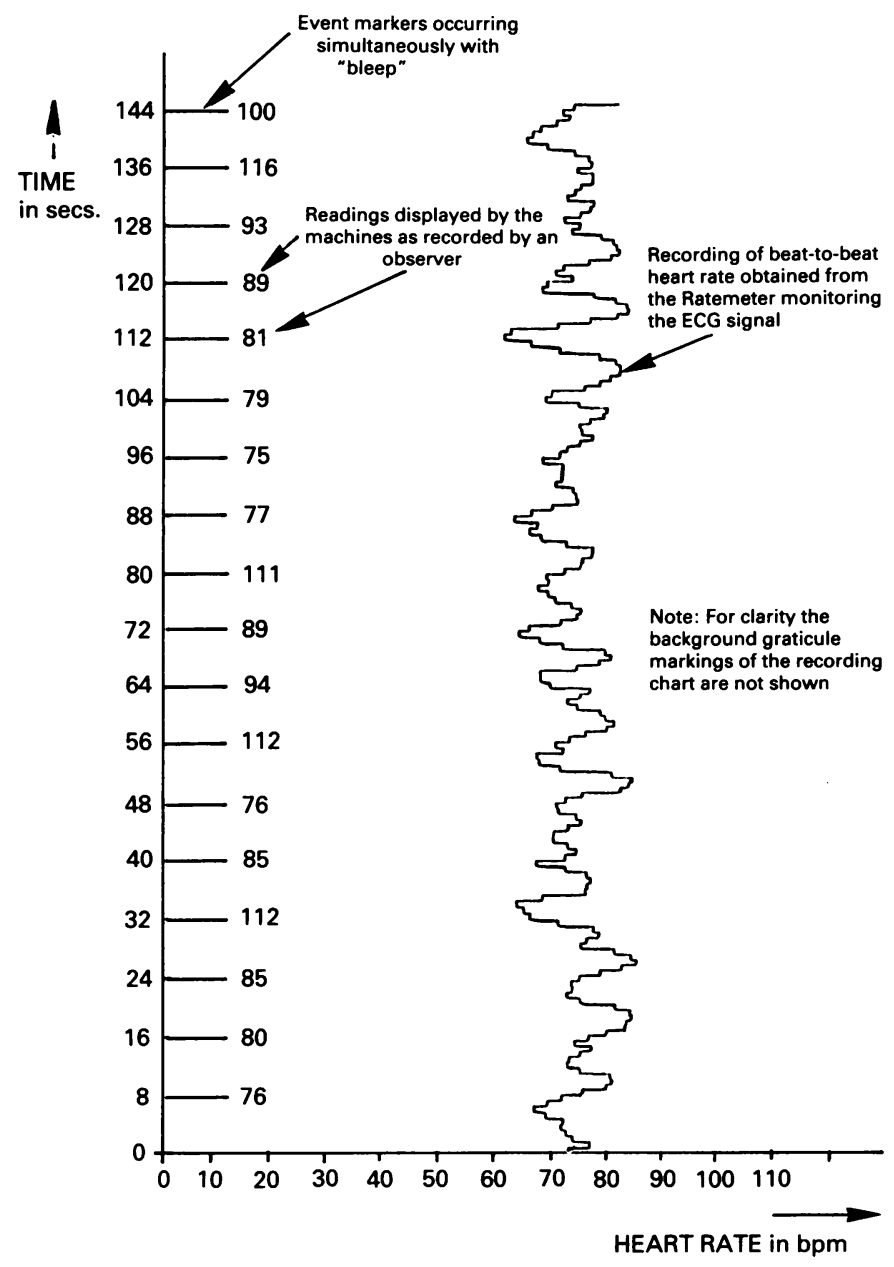

Fig. 1: A section of a typical chart recording from an exercise test.

machine in response to the sinewave signal are given in the table along with the heart rates corresponding to the frequency steps used in the test. Differences between the two sets of readings indicate measurement errors in the machine.

(b) Composite Signals Details of the response of each machine to the composite signals are also given in Table I. When the sequences of readings displayed were compared closely with the beat-to-beat time intervals and the corresponding heart rates of the composite signals the method of operation was established for each machine as follows: Machine A averages the inter-beat time intervals over two successive intervals and displays an equivalent heart rate, updating the reading on every second heart beat. Machine B measures the heart rate on a beat-to-beat basis without averaging but only updates the displayed reading on every fourth beat. Machine $C$ averages the inter-beat time intervals over a period of approximately 8 seconds and updates the reading displayed after each period. Machine $D$ continuously averages the heart rate with a time-constant of approximately 2-3 seconds. It responds to gradual changes in the heart rate while rejecting large short-term variations. The reading displayed is updated on every heart beat.

\section{Exercise Testing}

Readings listed beside the event markers on the chart are only samples taken at 8 second intervals of the readings displayed by a machine. Moreover, because of the response time of the subject the readings called out by him on hearing a bleep may not be exactly those present at the times the event markers appear on the chart. In addition, there is an offset between the pens of the two channels on the chart recorder which causes a time error between the traces. These factors combined make it impossible to establish an exact correspondence between readings obtained from the machines and those provided by the Ratemeter. This means that paired data cannot be established and consequently the usual statistical analysis of correlation cannot be performed. The nature of the data also makes statistical analysis of variance unsuitable.

Despite the difficulties outlined above, it is possible to establish a range on the Ratemeter recording within which each machine reading was determined. Thus each reading obtained from a machine can be compared with the beat-tobeat recording in a "window" near the event marker at which it is noted. When differences in the operation of each machine were also taken into account the window for comparison was established as extending between the event marker at which a given machine reading was noted and the previous marker for Machines A, B and D. In these cases each machine reading was compared with each individual beat-to-beat heart rate value within the corresponding window. For Machine $\mathrm{C}$, however, the window extended back to the second previous marker because of the longer averaging time of this machine. Readings obtained by the 8 second averaging from Machine $C$ had to be compared with a similar average, estimated from the beat-to-beat recording. This estimation was made manually by tracing a line carefully through the Ratemeter recording, averaging out large beat-to-beat variations and following those which occurred more slowly over several seconds. Readings from Machine $C$ were then compared with this tracing over the corresponding windows.

Significant differences between the machine readings and the beat-to-beat values which persisted over an entire window were noted. Differences of $10 \mathrm{bpm}$ or more were classified into one of three categories of errors namely: errors of 10-19 bpm, of 20-49 bpm and of $50 \mathrm{bpm}$ or greater. The total numbers of errors in each category were then determined for each test and converted into percentages of the total number of 50 readings. These figures are shown in Table II.

\section{DISCUSSION}

The electronic testing of the machines using a sinusoidal signal shows that they measure accurately under this condition and the generally small errors encountered are of little practical importance. Machines A, C and D displayed a reading of $118 \mathrm{bpm}$ in response to Composite Signal $A$ instead of the true average value of $140 \mathrm{bpm}$. This value is actually obtained by averaging two consecutive time intervals and calculating an equivalent heart rate from this. It can be shown, however, that the error introduced by this form of measurement for heart-rates above $\mathbf{4 0} \mathrm{bpm}$ is less than $\pm \mathbf{4 b p m}$ if the beat-to-beat variation in the heart rate is less than $40 \mathrm{bpm}$. This is verified by the readings displayed by these machines in response to Composite Signal B.

The accuracy requirements of heart rate monitors under practical operating conditions differ widely depending on the application. In order to highlight the unreliability of the machines under exercising conditions the authors proposed very lenient criteria for the assessment of machine performance. Maximum allowable percentages of erroneous readings in the three categories previously specified were proposed as follows: 


\section{TABLE ॥}

Results of exercise testing of the machines.

Figures given are percentages of the total number of 50 readings assessed in each test.

\begin{tabular}{|c|c|c|c|c|c|c|c|c|c|c|c|c|c|c|c|c|c|}
\hline \multirow[b]{2}{*}{ Test Condition } & \multirow[b]{2}{*}{ Error in bpm } & \multicolumn{4}{|c|}{$\begin{array}{l}\text { Machine A } \\
\text { Subject No. }\end{array}$} & \multicolumn{4}{|c|}{$\begin{array}{l}\text { Machine B } \\
\text { Subject No. }\end{array}$} & \multicolumn{4}{|c|}{$\begin{array}{l}\text { Machine C } \\
\text { Subject No. }\end{array}$} & \multicolumn{4}{|c|}{$\begin{array}{l}\text { Machine D } \\
\text { Subject No. }\end{array}$} \\
\hline & & 1 & 2 & 3 & 4 & & 2 & 3 & 4 & 1 & 2 & 3 & 4 & 1 & 2 & 3 & 4 \\
\hline & \pm 10 to \pm 19 & 14 & 0 & 2 & 0 & 0 & 0 & 0 & 0 & 0 & 0 & 22 & 4 & 8 & 0 & 10 & 0 \\
\hline \multirow[t]{3}{*}{ Sitting } & \pm 20 to \pm 49 & 24 & 2 & 6 & 14 & 0 & 0 & 0 & 0 & 2 & 2 & 54 & 0 & 0 & 0 & 14 & 0 \\
\hline & $> \pm 50$ & 38 & 0 & 8 & 20 & 2 & 0 & 0 & 0 & 0 & 0 & 0 & 0 & 0 & 0 & 0 & 0 \\
\hline & \pm 10 to \pm 19 & 12 & 6 & 2 & 0 & $*$ & * & 0 & 2 & 16 & 30 & 22 & 20 & 0 & 2 & 32 & 4 \\
\hline Walking & \pm 20 to \pm 49 & 30 & 30 & 28 & 38 & $*$ & $*$ & 88 & 32 & 2 & 18 & 70 & 70 & 0 & 0 & 36 & 0 \\
\hline \multirow[t]{2}{*}{$(3 \mathrm{~km} / \mathrm{hr})$} & $> \pm 50$ & 44 & 36 & 50 & 50 & $*$ & $*$ & 2 & 0 & 0 & 12 & 0 & 4 & 0 & 0 & 4 & 0 \\
\hline & \pm 10 to \pm 19 & 24 & 38 & 6 & 6 & * & * & 2 & 0 & 2 & 4 & 36 & 32 & 6 & 22 & 28 & 40 \\
\hline Jogging & \pm 20 to \pm 49 & 38 & 28 & 12 & 18 & $*$ & * & 42 & 16 & 74 & 2 & 52 & 22 & 22 & 8 & 42 & 0 \\
\hline$(5 \mathrm{~km} / \mathrm{hr})$ & $> \pm 50$ & 0 & 0 & 76 & 74 & $*$ & * & 36 & 12 & 8 & 0 & 0 & 0 & 44 & 0 & 4 & 0 \\
\hline
\end{tabular}

* no readings obtained.

$\begin{array}{ll}\text { errors of } 10-19 \mathrm{bpm} & 35 \% \\ \text { errors of } 20-49 \mathrm{bpm} & 20 \% \\ \text { errors of } 50 \mathrm{bpm} \text { or more } & 10 \%\end{array}$

These criteria allow a total of $65 \%$ of readings to have errors of $10 \mathrm{bpm}$ or more and a total of $30 \%$ of readings to have errors of $20 \mathrm{bpm}$ or more. The criteria set are not by any means stringent and could hardly be applied to the performance of a machine for use in more serious athletic training or in cardiac rehabilitation programmes.

The above criteria were then applied to the results of the exercise tests given in Table II. Machine A only met the proposed criteria on two subjects sitting relaxed. Machine $B$ met the criteria on all subjects but only when sitting relaxed. It was impossible to obtain any readings at all on two of the subjects when walking or jogging. In fairness to the manufacturer, it should be pointed out that this machine was not intended to be used while exercise is in progress. This is a severe drawback, as the heart rate measured while exercise is temporarily halted is not always a good indication of that prevailing during exercise (McArdle et al, 1969). Machine $C$ met the criteria on three subjects when seated and only on subject $A$ when walking and subject $B$ when jogging. Finally, Machine $D$ met the proposed criteria on all subjects when sitting, on all but one subject when walking and on only one subject when jogging.

\section{CONCLUSION}

None of the machines examined can be described as either accurate or reliable. Only Machine D met the lenient performance criteria on only one subject under all three test conditions. The machines assessed were unable to detect an exercising subject's pulse without picking up interference due to movement and giving grossly erroneous readings. This problem needs much attention if accurate and reliable heart rate monitors are to become available in the future.

\section{ACKNOWLEDGEMENTS}

The authors wish to express their gratitude to Mr. B. Donne of the Dept. of Physiology, Trinity College, for technical assistance and advice on the manuscript, and also to Mr. E. Mullins of the Dept. of Statistics, Trinity College, for advice on data analysis.

\section{References}

Adams, T. D., Yanowitz, F. G., Fisher, A. G., Ridges, J. D., Lovell, K. and Pryor T. A., 1981 "Noninvasive Evaluation of Exercise Training in College-Age Men". Circulation 64: 958-965.

Andrew, G. M., Oldbridge, N. B., Parker, J. O. et al, 1981 “Reasons for Dropout from Exercise Programmes in Post-Coronary Patients". Med.Sci.Sports Exercise 13: 164-168.

Blair, S.N., Goodyear, N. N., Gibbons, L. W. and Cooper, K. H., 1984 "Physical Fitness and Incidence of Hypertension in Healthy Normotensive Men and Women". JAMA 252: 487-490.

Fox, E. L., 1979. Sports Physiology. W. B. Saunders Co., Philadelphia pp. 226-229.

Glover, B. and Sheperd, J., 1978. The Runner's Handbook. Penguin Harmondsworth. pp. 41-44.

Graettinger, W. F., 1984 "The Cardiovascular Response to Chronic Physical Exertion and Exercise Training: An Echocardiographic Review". Amer.Heart J. 108: 1014-1018.

Harris, R., 1970. The Management of Geriatric Cardiovascular Disease. J. B. Lippincott Co., Philadelphia pp. 59-63.

Jensen, C. R. and Fisher, A. G., 1979. Scientific Basis of Athletic Conditioning, 2nd Edition. Lea and Febiger, Philadelphia pp. 232-237.

McArdle W. D., Zwiren, L. and Magel, J. R., 1969 “Validity of the Post-Exercise Heart-Rate as a Means of Estimating Heart-Rate During Work of Varying Intensities". Res.Quart.Amer.Assoc. Health Phys.Fitness 40: 523-528.

Morehouse, L. E., 1972. Laboratory Manual for Physiology of Exercise. Mosby Co., London pp. 63-74.

Paffenbarger, R. S. and Hyde, R. T., 1980 "Exercise as Protection Against Heart Attack". N.Eng.J.Med. 302: 1026-1027.

Paffenbarger, R. S., Hyde, R. T., Wing, A. L. and Steinmetz, C. H., 1984 "A Natural History of Athleticism and Cardiovascular Health". JAMA 252: 491-495.

Note: For further information regarding this study please contact the authors. - Ed. 